\title{
COMMUNICATION AND RATIONAL RESPONSIVENESS TO THE WORLD
}

BY

ROBERT EAMON BRISCOE

\begin{abstract}
Donald Davidson has long maintained that in order to be credited with the concept of objectivity - and, so, with language and thought - it is necessary to communicate with at least one other speaker. I here examine Davidson's central argument for this thesis and argue that it is unsuccessful. Subsequently, I turn to Robert Brandom's defense of the thesis in Making It Explicit. I argue that, contrary to Brandom, in order to possess the concept of objectivity it is not necessary to engage in the practice of interpersonal reasoning because possession of the concept is independently integral to the practice of intrapersonal reasoning.
\end{abstract}

1.

Philosophers of language are much divided when it comes to the question of whether and in what sense, if any, language is socially constituted. Perhaps the most familiar version of the debate concerns which notion of language - whether that of idiolect or sociolect - is fundamental for purposes of reflection on meaning and understanding. ${ }^{1}$ Are the semantic properties of idiolects to be explained by reference to the semantic properties of sociolects, or is it the other way around? ${ }^{2}$ Donald Davidson's position with regard to the role of the social in this context may, at first, therefore seem somewhat paradoxical. Following Quine, Davidson has long championed the notion of idiolect as fundamental for the theory of meaning. At the same time, however, in numerous articles written over several decades, he has defended the view that intersubjective communication is a metaphysically necessary condition of the existence of language and 
thought. ${ }^{3}$ The appearance of paradox is dispelled by Davidson's wellknown denial that the notion of sociolect plays any role when it comes to explaining the phenomenon of successful communication between speakers. ${ }^{4}$ For Davidson, successful communication is to be explained by mutual awareness of meaning in the context of utterance, not by mutual awareness of meaning in a common language. "There seems to me to be no reason, in theory at least," he writes, "why speakers who understand each other ever need to speak, or to have spoken, as anyone else speaks, much less as each other speaks" (1994/2005, p. 115). Language and thought are social, on Davidson's view, not because they require the existence of intersubjectively recognized linguistic conventions or norms, ${ }^{6}$ but rather because they metaphysically depend on linguistic interaction between speakers for their existence. In what follows, I shall refer to this view as the communication thesis.

Davidson starts from the idea that language and thought have an objective, representational character, i.e., from the idea that there is a potential contrast between what is said and what is so, between how things are taken to be in judgment and how things really are. This idea is sometimes made out in terms of the 'transparency' of belief from the first-person perspective. "It will be common knowledge," Richard Moran writes,

... among anyone with the concept of belief, that although one believes something as true, the fact believed and the fact of one's belief are two different matters. From within the firstperson perspective I acknowledge the two questions as distinct in virtue of acknowledging that what my beliefs are directed upon is an independent world, and they may therefore fail to conform to it. (Moran, 2001, pp. 61-62)

On this view, the (second-order) concepts of objective truth, error, and belief, form what Christopher Peacocke calls a 'local holism': to possess any one of the concepts in the trio is perforce to possess all three. The conceptual skills that enable us to make sense of other agents through attribution of mental states that stand in reason-giving relations to their actions are, at the same time, skills that enable us to think of ourselves as each having a certain subjective perspective on an objective, independent world.

While perhaps this much is widely accepted among philosophers of mind, the conclusion of Davidson's central argument for the communication thesis depends on two more controversial premises:

1) A creature that does not possess the concept of objectivity cannot be credited with either language or thought.

2) In order to possess the concept of objectivity it is necessary for a creature to be in linguistic communication with at least one other creature. 
Combining (1) and (2), it follows that linguistic communication is a necessary condition of the possibility of language and thought. (It also follows that having language and having thought are 'anatomic' properties of persons (Fodor and Lepore, 1992). A property $F$ is anatomic, if whenever it is the case that an object $x$ has $F$, then, necessarily, there exists some different object $y$ that also has $F$. Examples of anatomic properties include being a co-author, being married, and being in tune. For Davidson, if one person has language and thought, then, necessarily, there is at least one other person who also has language and thought.) It is in this sense, one that notably makes no appeal to the notion of sociolect, that language and thought are social in a philosophically profound sense for Davidson.

Davidson is not the only prominent philosopher of language to defend such a view. In Chapter 8 of Making It Explicit, Robert Brandom puts forward a much-elaborated version of Davidson's argument for the communication thesis. " Only communities, not individuals," on Brandom's construal of its conclusion, "have original intentionality" (1994, p. 61). (So expressed, the communication thesis is given an obvious Hegelian flavor.) Perhaps to a greater extent than the other two main architectonic ideas in Making It Explicit - the idea that meaning is 'normative' and the idea that meaning is inferential role - the communication thesis is burdened with the task of supporting the unique social-deontological approach Brandom takes towards language in the book. "The via media pursued here," he writes in the preface, "eschews intentional or semantic specifications of behavior but permits normative and therefore social specifications of what is in fact linguistic behavior" (1994, p. xv). Although I think that the very idea of such a deontological via media is extremely problematic, ${ }^{8}$ the present point is that it is only issue of a promissory note at the beginning of Making It Explicit to defend the communication thesis in Chapter 8 that gives provisional license to pursuit of that middle path in preceding chapters. There is thus much riding on the cogency of the argument presented in Chapter 8 , for without the buttress provided by the communication thesis it is not clear how much of the broad project undertaken in Making It Explicit is otherwise adequately motivated.

The communication thesis is perhaps one of the better-known versions of the view that language and thought are social in a philosophically profound sense. In this paper, I focus on the crucial second premise in the Davidson-Brandom argument for the thesis, namely, that, in order to possess the concept of objectivity, it is necessary for a creature to be in linguistic communication with at least one other creature. I first explain how Davidson's deployment of the communication thesis can be viewed as a response to a problem about the possibility of empirical content that arises when an idea central to what McDowell (1994) calls 'minimal 
empiricism' is rejected. I then argue that there are two serious problems with Davidson's defense of the communication thesis, the latter of which shows that there can be no cogent repudiation of minimal empiricism. Subsequently, I turn to Robert Brandom's defense of the communication thesis in Making It Explicit. According to Brandom:

... it is precisely the objectivity of conceptual norms, when properly understood, that leads to the requirement that the practices in which such norms are implicit be social practices. The objective representational dimension of conceptual content ... turns out to depend on the social articulation of the inferential practice of giving and asking for reasons. (1994, p. 54)

I argue, however, that grasping the distinction between appearance and reality, between what is taken to be the case and what is the case, is integral to the first-person stance of the rational agent and, so, already part of being in a position to play the Sellarsian game of giving and asking for reasons. In order to have the concept of objectivity, is not necessary, contrary to Brandom, to engage in the practice of interpersonal reasoning because having the concept is already and independently integral to the practice of intrapersonal reasoning.

\section{2.}

Before proceeding, it is necessary to make a couple of preliminary remarks. First, it is important to be clear that neither premise (1) nor (2) in the argument for the communication thesis is intended as a psychological claim about human cognitive ontogeny. Premise (2), for example, is not intended as the claim that acquisition of the concept of objectivity (and its cognates) is psychologically enabled by the ability to communicate with others. Rather, it is intended as an a priori constitutive claim, a claim about what it is to have the concept of objectivity. Indeed, it cannot be intended as a psychological claim if what is at issue is a supposed metaphysically necessary condition of the existence of language and thought a 'transcendental' condition of their possibility as it were.'

Second, the communication thesis neither implies nor is implied by social externalism (or 'social anti-individualism,' as it is sometimes called). Social externalists adhere to the view that in certain circumstances namely, those assumed to obtain in Tyler Burge's well-known thoughtexperiments - the meanings of words in a speaker's idiolect and the conceptual contents of her thoughts partly depend for their individuation on facts about her social environment. The thesis does not imply social externalism because it is compatible with the Quinean idea that, in the context of interpretation, facts about the meanings of a speaker's words depend solely on public facts about the use she as an individual makes of them. ${ }^{10}$ 
(For discussion, see Bilgrami, 1992, chap. 3.) Moving in the other direction, the thesis is not implied by social externalism because social externalism does not entail that interpersonal linguistic interaction is metaphysically necessary for having either language or thought. Social externalism is a thesis about the individuation or correct explication of certain representational contents. Unlike the communication thesis, it makes no a priori claims about the general conditions of the possibility of representational content. ${ }^{11}$ It does not claim, in particular, that "speaking a language requires that there be an interpreter" (Davidson, 1992/2001a, p. 114). It is thus potentially misleading when Davidson broadly characterizes social externalism as maintaining that "the contents of our thoughts depend, in one way or another, on interaction with other thinkers" (2001b, p. 2). Such characterization covers over fundamental differences between the two views.

As Bjørn Ramberg observes, the view to which Davidson adheres "makes the presence of thought contingent not on the presence of in-principle interpretable patterns of events, but on actual interpretation" (2001, p. 228). The third point is that it is important to distinguish this view, i.e. the communication thesis, from Daniel Dennett's influential and well-known view that a creature is an intentional system just in case its behavior can be usefully explained and predicted by attributing (appropriately related) beliefs and desires to it, i.e., by taking up the "intentional stance" towards it. This latter view is significantly weaker because, according to Dennett, the patterns of behavior identified from the intentional stance are real patterns, "really, objectively there to be noticed or overlooked" (1987, p. 37). ${ }^{12}$ The relevant patterns are not, contrary to Brandom's "phenomenalist" assimilation of Dennett's view in Making It Explicit (pp. 55-62), merely in the eye of the beholder; they are not dependent for their existence on their actually being detected by someone. (William Child, for purposes of distinguishing the stronger view, refers to it as 'constitutive interpretationism' (1994, p. 47). Dennett has stated in conversation that he rejects constitutive interpretationism.) The difference between Dennett, on the one hand, and Davidson and Brandom, on the other, broadly speaking, then, is the difference between saying that a creature has intentional states only if it is interpretable as having them and saying that a creature has intentional states only if it is actually interpreted as having them. ${ }^{13}$

\section{3.}

In the phenomenon known as "joint attention" (or "joint awareness") two individuals attend to the same thing at the same time and, crucially, both are aware that both are aware of this fact. Joint attention and the kind of ostensive learning it enables are fundamental to the process of 
acquiring a first language (Tomasello, 1999, 2003). It is the triangle of child, adult, and jointly attended circumstance that makes incipient forms of intersubjective understanding possible. Michael Tomasello writes:

$\ldots$ at around nine to twelve months of age a new set of behaviours begins to emerge that ... are triadic in the sense that they involve a coordination of their interactions with objects and people, resulting in a referential triangle of child, adult, and the object or event to which they share attention. Most often the term joint attention has been used to characterize this whole complex of social skills and interactions ... Most prototypically, it is at this age that infants for the first time begin to flexibly and reliably look where adults are looking (gaze following), to engage with them in relatively extended bouts of social interaction mediated by an object (joint engagement), to use adults as social reference points (social referencing), and to act on objects in the way adults are acting on them (imitative learning). (1999, p. 62)

Joint attention, however, is also fundamental to full-blown communication by means of language. Successful communication between mature speakers typically involves not only joint awareness of the world, in particular, the perceptible context in which communication takes place, but also joint awareness of the meaning of communicative partners' utterances (Campbell, 2002, chap. 8; Peacocke, 2005). It is this sort of mature, triangular communicative situation that is of primary interest to Davidson. I shall follow him, below, in referring to the joint attention situation in which two competent speakers communicate with one another by knowingly correlating their respective linguistic responses to a certain perceptible state of affairs as triangulation.

Now there is nothing contentious about the claim that what one might call 'proto-triangulation' is psychologically necessary when it comes to firstlanguage acquisition. (Unlike Davidson's triangulation, proto-triangulation would not require that both individuals already have full-blown language and so could potentially explain how one of them could be brought to have it.) Indeed, from a psychological standpoint, it is not clear how else the trick could be pulled off. For precisely this reason, much empirical research has been done on how children learn language from adults in 'joint attention triangles.' (For reviews, see Malle et al., 2001 and Eilan et al., 2005.) Davidson, however, makes a far more radical claim than that some form of proto- or incipient triangulation is psychologically necessary for first-language acquisition. The kind of intersubjective, communicative interaction that is involved in mature triangulation, he maintains, is an a priori, metaphysically necessary condition of the possibility of the existence of language and thought. In "The Emergence of Thought," he writes:

... the triangle ... is essential to the existence ... of thought. For without the triangle, there are two aspects of thought for which we cannot account. These two aspects are: the 
objectivity of thought, and the empirical contents of thoughts about the external world. (Davidson, 1997/2001a, p. 129)

For Davidson, triangulation accounts for both aspects at the same time. The successful correlation of linguistic responses it enables accounts for their empirical content, while the possibility of failure of correlation of linguistic responses accounts for, or rather makes 'conceptual space' for, application of the concept of objectivity. But why does Davidson think that triangulation plays any such enabling role? What problem about accounting for the two aspects of thought mentioned in the passage motivates Davidson's appeal to triangulation?

\section{4.}

The problem in Davidson's writings of accounting for the two aspects of thought - its objectivity and its empirical contentfulness - can be viewed as a consequence of his rejection of what John McDowell (1994) calls 'minimal empiricism.' Minimal empiricism combines two main ideas: The first idea is that the empirical contentfulness of language and thought requires for its intelligibility that perceptual belief be conceived as rationally responsible to the perceptible facts. Perceptual beliefs must be conceived as answerable to the world for their truth if it is to be intelligible how they and the non-perceptual beliefs they justify can be bearers of empirical content. ${ }^{14}$

The second idea is that perceptual belief requires for its intelligibility that an individual be conceived as rationally responsive to the perceptible facts to which her perceptual beliefs are rationally responsible. ${ }^{15}$ (For substantial articulation and defense of this view, see Brewer, 1999.) According to minimal empiricism, the fact that an individual's perceptual belief, say, that the leaves on a certain maple tree are red, has a certain empirical content is to be connected with her abilities perceptually to assess the rational credentials of that belief in view of what is perceptibly the case. In this example, it is to be connected with her ability to perceive whether or not the leaves are red. The second idea thus qualifies the first idea by tethering rational responsibility - i.e., answerability to the facts - to rational responsiveness - i.e., the ability to answer in view of the facts.

McDowell puts the two ideas together as follows:

... thinking that aims at judgment, or at the fixation of belief, is answerable to the world for whether or not it is correctly executed. And now a small step away from that abstract formulation takes us to a minimal, and one might think indisputable, empiricism: in the sorts of case that must come first for reflection on the very idea of directedness at the world, the world's verdict, to which thinking must be answerable if it is to be thinking at all, is delivered by way of a pronouncement from ... 'the tribunal of experience'. (1996, pp. 231-32) 
The passage combines the first idea with the second in binding the notion of empirical contentfulness to the notion of perceptual experience as providing a 'tribunal' for empirical thinking and, thereby, to the notion of rational responsiveness. For McDowell, perceptual experience is a mode of rational responsiveness to the facts to which one's perceptual beliefs are rationally responsible. Minimal empiricism, in coupling the two ideas, denies that there can be such a thing as rational responsibility without rational responsiveness. ${ }^{16}$

Davidson rejects the second idea comprised by minimal empiricism. He denies that perception can intelligibly serve as a court of appeals for empirical belief, that, as McDowell puts it, "When we trace the ground for an empirical judgement, the last step takes us to experiences" (1994, p. 10). The problem, according to Davidson, is that the relation in which perception stands to belief is not logical or justificatory, "since sensations are not beliefs or other propositional attitudes" (1983/2001a, p. 143). Rather, the relation is causal: "Sensations cause some beliefs and in this sense are the basis or ground of those beliefs. But a causal explanation of a belief does not show how or why the belief is justified" (ibid.). However, if its perceptual ancestry does not provide the justification of a belief, then what does? Without an answer to this question, we lose our purchase on the idea of belief as a mental state whose content depends on the particular way it is rationally responsible to the world for its truth. ${ }^{17}$

The problem with looking to perception for justification, as Davidson sees it, comes out very clearly in the following passage from "Empirical Content":

It should be obvious that no appeal to perception can clear up the question [of] what constitutes a person's ultimate source of evidence. For if we take perception to consist in a sensation caused by an event in the world (or in the body of the perceiver), the fact of causality cannot be given apart from the sensation, and the sensation cannot serve as evidence unless it causes a belief. But how does one know that the belief was caused by a sensation? Only further beliefs can help.

There is, then, good reason to conclude that there is no clear meaning to the idea of comparing our beliefs with reality or confronting our hypotheses with observations. (1982/ 2001a, p. 164)

But, if there is no clear meaning to the idea of perceptually comparing our beliefs with reality or confronting hypotheses with observations - as required by minimal empiricism - then it is not obvious how there can be clear meaning to the idea that empirical language and thought are rationally responsible to how things are in the world. How can there be rational responsibility and, so, empirical contentfulness, without rational responsiveness? As McDowell expresses the worry here, "What we wanted to conceive as exercises of concepts threaten to degenerate into moves in a self-contained game" (1994, p. 5). 
Davidson's theory of triangulation is intended to assuage precisely this worry. It is intended as an answer to the question: How can there be rational responsibility and, so, empirical contentfulness, without rational responsiveness? His answer starts with the idea that while the cause of a response (a putative belief or utterance), does not justify the response, it does, at least in the epistemically most basic cases, fix its empirical content. But how given Davidson's repudiation of the second idea comprised by minimal empiricism is it determined what in the world is the cause of a response? If, from the first-person point of view, "the fact of causality cannot be given apart from the sensation, and the sensation cannot serve as evidence unless it causes a belief," then how is it possible to key a response to an event or type of event in the world?

It is Davidson's suggestion that no solution to the problem is forthcoming if we focus on the causal relation between the responses of a single creature and the stimuli that cause them. In "Conditions of Thought," he writes:

If we consider a single creature by itself, its responses, no matter how complex, cannot show that it is reacting to, or thinking about, events at a certain distance away rather than, say, on its skin.

The problem is not, I should stress, one of verifying what objects or events a creature is responding to; the problem is that without a second creature interacting with the first, there can be no answer to the question. And if there can be no answer to the question what a creature, means, wants, believes or intends, it makes no sense to hold that the creature has thoughts. (Davidson, 1989, p. 198) ${ }^{18}$

It seems clear that the problem Davidson adumbrates here is a version of the so-called "distality problem" faced by causal theories of meaning and mental content (Fodor, 1990, pp. 57-60). This is the problem that a response reliably keyed to a certain event-type in a causal chain of covarying event-types is necessarily keyed to every event-type in that chain. If response-type $R$ is keyed to distal event-type $F$ (the presence of a rabbit) and, if $F$ causally covaries with proximal event-type $G$ (a certain pattern of retinal stimulation), then $R$ is also keyed to $G$. Without a solution to the distality problem, there is no saying whether the event-type to which a response-type is reliably keyed is located outside a creature, or on its sensory periphery, or somewhere further in. (For discussion, see Jacob, 1997, pp. 100-104.)

The putative problem, it is important to emphasize, is not epistemological. It is not that it is merely impossible for us to know which eventtype is the relevant environmental cause of a creature's responses, and so what its responses mean. Rather, the problem is ontological: it concerns 
whether there is such a thing as the relevant environmental cause. In this respect, there is an analogy - more than once noted by Davidson himself - with Saul Kripke's (1982) skeptical interpretation of the putative rulefollowing paradox. ${ }^{19}$

This is where triangulation enters the picture. It is not the observer who perceptually judges that $p$ who keys her response to an event in the world, rather but another person, an interpreter, with whom she is in communication. Davidson's approach is premised on the idea that it is possible to, so to speak, divide the perceptual labor that remains undivided in minimal empiricism. The task of responding to the perceptible facts is delegated to the observer, while the task of assessing the correctness of her response in light of those facts is delegated to the interpreter. The interpreter, in correlating the observer's linguistic response to a perceptible event in the world with her own response, fixes the empirical content of the observer's response. At the same time, the possibility of failure of correlation of responses accounts for, or rather makes 'conceptual space' for, application of the concept of objectivity. What appears from the first-person perspective as the distinction between what is said and what is so, between what is taken to be the case and what is the case, is explained in terms of what conceptually appears from the interpreter's perspective as the potential conflict between the observer's response and her own. (For example, the observer reports that a duck is visible when the interpreter spies only a decoy.) Interpretation, however, is a two-way street: whether a party plays the role of interpreter or observer is relative to point of view.

Davidson thus repudiates the second idea comprised by minimal empiricism, the idea that when we trace the ground for an observer's perceptual belief, the last step takes us to observer's own experiences. According to Davidson's "non-individualist" approach, justification or external constraint, so to speak, lies on an axis orthogonal to the causal line between the facts and the perceptual beliefs they elicit. Whether an observer's perceptual belief is justified is something that can only be discerned from sideways on, from the point of view of the interpreter. It is in this sense that Davidson's approach is premised on the possibility of dividing the perceptual labor that remains undivided in minimal empiricism.

\section{6.}

Ignoring the details, there are two main problems with Davidson's account of how there can be rational responsibility without rational responsiveness. The first is that communication cannot be a necessary condition of the existence of empirically contentful language and thought because communication presupposes the existence of empirically contentful language 
and thought. Successful communication about a jointly attended state of affairs $p$, one might object, presupposes not only joint awareness of the world, but also joint awareness of meaning. So it cannot be communicative success that makes such mutual knowledge first possible. Communicative success presupposes that there are facts about what communicative partners mean by their respective words (in the contexts in which they are uttered) and, so, cannot bring those facts into existence.

The difficulty with this first blush objection, however, is its talk of presupposition. Communicative success, one might argue, does not presuppose joint awareness of the meaning of an utterance, it is that joint awareness: I utter a sentence that I understand in context to mean $p$ and you understand in context that I have said that $p$. As Peacocke writes, "The utterer aims to bring about a state of joint awareness whose content involves the meaning, or, better, the intentional content of the utterance itself" (2005, p. 315). I take it that this is something Davidson himself would want to say.

The problem, however, now comes back with full vigor. For, in attempting to explain what it is for one speaker to communicate with another, we have made reference to a complex (presumably implicit) linguistic intention to bring about a state of joint awareness whose content involves the meaning of an utterance. It is hard to see that it is possible make sense of the phenomenon of successful communication without appeal to such complex linguistic intentions. But, if that is so, then communication cannot be a conceptually necessary condition of the existence of language and thought because, in the sense just explained, communication presupposes the existence of language and thought.

Indeed, reflection on the broader phenomenon of joint attention implicates the very notions whose possibility Davidson had intended to explain by appeal to the phenomenon. Consider Peacocke's (2005) account of full joint attention by agents $x$ and $y$ to a state of affairs $s$ :

(a) $x$ and $y$ are attending to $s$;

(b) $x$ and $y$ are each aware that their attention in (a) has mutual open-ended perceptual availability; and

(c) $x$ and $y$ are each aware that this whole complex state of awareness (a) - (c) exists. ${ }^{20}$

Here "mutual open-ended perceptual availability" obtains, when, according to Peacocke, "Each perceives that the other perceives that $s$ obtains; and if either is occurrently aware that the other is aware that he is aware... [the ellipsis indicates an open-ended number of possible iterations] that $s$ obtains, then the state of affairs of his being so occurrently aware is available to the other's occurrent awareness" (2005, p. 302). 
Now, even if one would wish to qualify Peacocke's elegant account, what it makes clear is that full joint attention, including the full joint awareness of meaning involved in successful communication, is possible only if each participant is capable of forming higher-order beliefs about its own mental states and those of the other. But, if that is so, then triangulation cannot be a conceptually necessary condition of the existence of thought because, in the sense just explained, it presupposes the existence of thought.

\section{7.}

The second problem with Davidson's answer to the question "How can there be rational responsibility and, so, empirical contentfulness, without rational responsiveness?" can be brought out by reflecting on the interpreter's supposed role in the context of triangulation. According to Davidson in "Empirical Content":

It is not the speaker who must perform the impossible feat of comparing his belief with reality; it is the interpreter who must take into account the causal interaction between world and speaker in order to find out what the speaker means, and hence what he believes. Each speaker can do no better than make his system of beliefs coherent, adjusting the system as rationally as he can as new beliefs are thrust on him. (1982/2001a, p. 174)

But how, one might ask, does the interpreter perform the feat - impossible for the observer - of comparing the observer's belief (or putative utterance expressive of belief) with reality? From the first-person perspective, the interpreter is in no better position than the observer when it comes to keying her own beliefs to their worldly causes. In particular, she is in no better position than the observer when it comes to determining the causes of her own beliefs about what the observer's utterances mean, i.e., the causes of her own beliefs about the causes of the observer's utterances. If, in general, from the first-person perspective, it is impossible, as Davidson says, to compare one's own beliefs with reality, then it is impossible for the interpreter to compare her own beliefs about what is causing the observer's utterances with reality. The problem is that an interpreter is just an observer of another observer, and an observer, on Davidson's 'non-individualist' theory of perception, is not rationally responsive to the facts to which her beliefs are rationally responsible.

Here is another way of making the point. For purposes of argument, let us say that instead of beliefs, an observer considered by herself, i.e., in notional isolation, has non-intentional schmeliefs. ${ }^{21}$ Now, my response to Davidson is that if, as he centrally maintains, it is impossible for a putative observer to identify the causes or assess the correctness of the schmeliefs she forms, indeed, if the question of correctness cannot even arise for her schmeliefs, then bringing in another speaker can make no 
improvement on her predicament. In particular, it cannot transform her schmeliefs into beliefs. For, in the scenario imagined here, other people and, in particular, their sayings and doings, are just additional causes of schmeliefs. The answer to the question "How can there be rational responsibility and, so, empirical contentfulness, without rational responsiveness?" is that there can't be.

If we step back now, the preceding discussion has, I think, enabled us to make the following general observation: An objective check on empirical thinking cannot first 'emerge' out of communicative interaction because communicative interaction - as opposed to mere sounding-off and gesticulating - requires that one be rationally responsive in perception to the facts to which one's interlocutors' (and one's own) empirical judgments are rationally responsible. In other words, in communicating about a shared environment, an individual $A$ 's empirical judgments can intelligibly serve as a source of rational constraint on another individual $B$ 's empirical thinking only provided that $B$ herself is able perceptually to assess the correctness of $A$ 's empirical judgments. But, if this is right, then, in general, other individuals' empirical judgments cannot be the source of rational constraint on B's empirical thinking. Rather, the fundamental source of rational constraint on B's empirical thinking, as McDowell rightly insists, is her own rational responsiveness to the world. If other individuals' judgments are to be a source of rational constraint on B's thinking - as they surely often are - then B must already be in rational (and not merely causal) contact with the world to which those judgments are rationally responsible.

To deny this, I would suggest, is to cling to the idea that intersubjective interaction is a magic ingredient that somehow turns what Simon Blackburn refers to as a 'wooden' picture of language into a 'full' one. According to the wooden picture, "the only fact of the matter is that in certain situations people use words, perhaps with various feelings like 'that fits', and so on.... But just because of this, it seems to make no room for the idea that in using their words they are expressing judgments" (1981, p. 183). The problem with the idea that intersubjective interaction can somehow turn a wooden picture of language into a full one, as Blackburn duly notes, is that "a lot of wooden persons with propensities to make noises is just more of whatever one of them is." 22

A related point to be made in ending this section concerns the claim that it is the possibility of disagreement in responses in the context of triangulation that creates 'conceptual space' for the application of the concept of error and, so, for rational constraint on perceptual judgment. ${ }^{23}$ The problem with this claim is that mere failure of expected correlation of responses is not indicative of error unless the responses are tokens of a response-type with a certain intentional content. Mere deviation in 'wooden,' non-intentionally characterized reactions, after all, would not indicate more than that there are different propensities to make noises 
at work. But, then, the criterion of error is clearly not failure of correlation in intersubjective responses, but rather straightforward failure of correlation between an individual tokening of a response-type and the event-type it represents. So the presence of a second creature with which it is possible to triangulate seems irrelevant. (For a similar objection, see Bridges, forthcoming.)

\section{8 .}

According to Brandom, only on McDowell's 'individualist' assumption that the one whose judgment is justified must be the same one who can appeal to the external constraint in justifying it is it correct to conclude that "When we trace the ground for an empirical judgment, the last step takes us to experiences" (Brandom, 1998, pp. 373-374). In attempting to deflect the charge of individualism Brandom brings against minimal empiricism, ${ }^{24}$ McDowell writes: "A rational animal could not have acquired the conceptual capacities in whose possession its rationality consists except by being initiated into a social practice. But as I see things, the capacities transform their possessor into an individual who can achieve standings in the space of entitlements by her own efforts" (McDowell, 2002, pp. 104-105). However, it was precisely the idea that an individual can achieve such standings by her own efforts, the second idea comprised by minimal empiricism, that invited Brandom's charge of individualism. What the foregoing discussion has shown is that the charge of individualism, in the sense in which Brandom is using the term, is one to which McDowell should plead guilty. The individualist orientation of minimal empiricism is a feature, not a bug. (What is more, it is a feature has the merit of being defensible apart from McDowell's controversial characterization of experience in Mind and World as "an actualization of conceptual capacities in sensory consciousness itself.") Indeed, I have suggested that, if successful communication is in fact possible, then there can be no cogent repudiation of the second idea comprised by minimal empiricism. This becomes only clearer when we turn to examine Brandom's own defense of the communication thesis in Making It Explicit.

\section{9.}

In Chapter 8 of Making It Explicit, Brandom attempts to show that the objective, representational character of language and thought can only be explained in terms of the social or communicative dimension of linguistic practice. This, of course, is the crucial second premise in the argument for the communication thesis. According to Brandom, the representational 
dimension of propositional content arises out of the difference in perspective between producers and consumers of claims in what Wilfrid Sellars called "the game of giving and asking for reasons." Brandom explains this difference in terms of an interpretation of the distinction between de dicto and de re attributions of beliefs. An attribution in the de dicto style, according to Brandom, specifies the content of the attributed belief from the perspective of the target of attribution, the one who makes a claim, who produces a reason. It specifies the content in a way that the target herself would be prepared to acknowledge. (Tiny Tim believes that Santa Claus is kissing his mother < attributee's perspective>.) Hence this style of attribution is that appropriate to psychological explanation. An attribution in the de re style, by contrast, specifies the content from the perspective of the one who attributes the belief, who assesses the claim, who consumes the reason. (Tiny Tim believes of his father that he is kissing his mother <attributer's perspective>.)

What follows from the assertion of a claim, from the expression of a belief, clearly depends upon what other claims or beliefs serve as collateral premises in the inference. In ascertaining what follows from a claim, a speaker or 'deontic scorekeeper', to use Brandom's vocabulary, has a choice to make: she can either assess its consequences from her own doxastic perspective or from that of the speaker to whom the claim is attributed. In the de dicto mode of attribution, she assesses the claim's consequences against the backdrop of claims that she attributes to the other speaker. In the de re mode of attribution, by contrast, she assesses the claim's consequences against the backdrop of claims that she herself would endorse or acknowledge as correct. ${ }^{25}$

De dicto and de re attributions thus "specify the single conceptual content of a single belief in two different ways, from two different perspectives, in two different contexts of auxiliary commitments" (Brandom, 2002, p. 102). If Mary believes (de dicto) that the mysterious stranger stole the silver candlesticks and, if the mysterious stranger unbeknownst to Mary is none other than Detective Shade in disguise, then Mary believes (de re) of Detective Shade that he stole the silver candlesticks. If, unlike Mary, I know that the mysterious stranger is none other than Detective Shade, then, unlike Mary, I also know that she believes of Detective Shade that he stole the silver candlesticks, that she is unwittingly committed to the truth of that claim. This example illustrates how the inferential significance of a claim varies with doxastic perspective.

\section{0.}

Brandom's leading idea in this context is that what appears from the firstperson perspective as the distinction or potential gap between what is said 
and what is so, between what is taken to be the case and what is the case, is to be explained in terms of what appears from the third-person perspective as the distinction between a speaker's merely attributing commitment to a claim to another speaker and actually endorsing or undertaking commitment to that claim herself. "From the point of view of each scorekeeper, there is for every other interlocutor a distinction between what commitments that individual acknowledges and what that individual is really committed to... But how this line is drawn in particular varies from scorekeeper to scorekeeper" (1994, p. 597). Hence, on Brandom's account, the possibility of error, returning to the first-person perspective, is grasped as the possibility of withholding endorsement of a claim that one attributes to another speaker. ${ }^{26}$ It follows that "there is no pattern of [linguistic] moves a single individual might make that would confer propositional contents with objective truth conditions on her utterances" (1994, p. 158), since it is only in the social context of the game of giving and asking for reasons that the concept of error and, so, the distinction between what is subjectively taken to be so and what objectively is so, finds application. This is Brandom's case for the crucial second premise in the argument for the communication thesis.

\section{1.}

The most obvious problem with Brandom's case for the second premise is that he provides no reason to think that the objective-subjective distinction can only be explained in intersubjective terms, i.e. in terms of attributions of beliefs to other speakers. That is, he does not show that linguistic communication is actually a necessary condition of grasping that distinction. Indeed, the distinction seems clearly to have (at least) two familiar and fundamental intrasubjective applications. Consider, first, self-knowledge about one's past beliefs. Assume that I once believed (de dicto) that a certain mysterious stranger stole a pair of silver candlesticks. Also assume that I now not only know that the claim I made was false, but that the mysterious stranger was none other than Detective Shade in disguise. It follows that I now know that I once believed (de re) of Detective Shade that he stole the silver candlesticks. The dictum to which I was then committed and, so, retrospectively attribute to my past self, is one that I now no longer endorse by virtue of beliefs I have since acquired about the res in question, i.e., Detective Shade.

Another intrasubjective application of the objective-subjective distinction is familiar from everyday reasoning and hypothesis mongering. Suppose I am in the library and think the thought that Behemoth can wait for his walk until I have finished working here. In mentally testing this hypothesis, I reflect on past instances in which I kept the dog waiting at 
home for his walk and recall unpleasant counterexamples on the carpet by the door. Recognizing my thought as the product of wishful thinking - and, so, in Brandom's terms, withholding endorsement from it - I hurry home.

Brandom provides no reason to suppose that either familiar intrasubjective application of the distinction between attributing or countenancing a claim and actually endorsing it is derived from its intersubjective use. But in order to motivate the crucial second premise in the communication thesis, he needs to show that such intrasubjective applications are in fact parasitic on their intersubjective applications. That is, he needs to block the availability of such a 'naïve' response as that made here.

\section{2.}

Part of what it means to say that thought has an objective, representational character, that thought is as it were transparent to the world, is that when one addresses oneself to the first-person, present-tense question "Do I believe that $p$ ?" the deliberation in which one engages involves the same sorts of considerations as would be involved in addressing oneself to the corresponding question about the world, i.e., "Is it the case that $p$ ?" Knowing one's own mind in the case of one's beliefs requires that one be able to make up one's mind and, in order to make up one's mind, one appeals, as Moran (2001) puts it, to "one's sense of the best reasons." ${ }^{27}$ But, in appealing to one's sense of the best reasons, one appeals not to the psychological fact that one believes that $p$, but rather to the putative fact that $p$ itself, a fact whose obtaining one thinks of as independent of one's belief. One would not be rational were one to approach the question of what one believes from the third-person, attributional perspective of the intentional interpreter, of one engaged in psychological explanation. ("I may not know what I think until I see what I say," E. M. Forster once quipped, but my relation to what I say and, so, to what I think is not that of a detached observer.) From the first-person perspective, one asks of oneself not the attributional question "What do I believe?," but the deliberative question "What am I to believe?"

"Any representational state," Moran writes, has "a dual aspect, one under which it is treated as transparent to the world in a certain way, another under which it makes a contribution to the behavior of the agent. Naturally, these different interests in belief are not restricted to the firstand third-person uses, respectively" (2001, p. 130). The point I wish to make now, in closing, is that recognition of the dual aspect of belief - of its objective side facing the world and its subjective side facing the agent - is in fact integral to the first-person stance, to the reflective consciousness of a rational agent. In what follows, I argue that the fact that the 
second, subjective aspect of belief is not and, for a rational agent, cannot be restricted to its third-person use obviates Brandom's approach to the problem of objectivity.

It is a familiar observation that the presumption of rationality (or the 'principle of charity' as it is sometimes called) is a constitutive part of the practice of engaging in third-person psychological explanation. Indeed, as Davidson and Dennett both emphasize, the presumption that a person is by and large rational and the presumption that she has identifiable propositional attitudes by appeal to which it is possible to explain her actions are one and the same. An intentional interpreter attempts to make rational sense of the agent's actions, and when the agent's actions make no rational sense, when they cease to be intelligible qua actions, they cannot straightforwardly be interpreted in intentional terms. ${ }^{28}$

Now, as I have already mentioned, one would not be rational were one to approach the question of what one believes from the third-person, attributional perspective of the intentional interpreter. A rational agent's belief, Moran writes:

is not for him a psychological datum that could even in principle justify his behavior purely in its role as a psychological state.... On the other hand, a rationalizing interpreter will take that behavior to be rationalized by the belief, whether it is true or false. The interpreter can afford to treat the belief as a psychological datum and go on from there to use it in a rationalizing explanation. The agent himself does not have this option, and ... he would not be rational if he did. And rationalizing interpretation, of all things, must seek to preserve the assumption of the subject's rationality. So the interpreter's stance and its success presuppose the stance of the reasoning agent; and further, they presuppose that belief is treated differently from within the two stances. (2001, p. 129)

The final point I wish to make now is that the interpreter's presumption of rationality also comprises the presumption that the reasoning agent, in critical reflection, recognizes that her beliefs are rationally responsible to an independent world for their truth, and so may fail to conform to it. Moran writes that "Beliefs 'aim at truth' and do not enter into ... reasoning in a way that brackets the question of their truth" (2001, p. 130). While it is no doubt right that it is what is believed, the putative fact that $p$, and not one's belief that $p$ that plays a role in first-person reasoning, a rational agent nonetheless recognizes that the outcome of her reasoning is something that may fail in particular cases to conform with the world. Moran makes much of the fact that, from the first-person perspective, a question of the form "Do I believe there will be a third world war?" and a question of the form "Will there be a third world war?" are equivalent in the deliberative demands they respectively make. ${ }^{29}$ In both cases, one looks to the world, to the same outward circumstances, for an answer. But one would not be rational were one to fail to recognize a distinction between the two kinds of questions and their answers, that is, between justification by 
one's own lights and truth. A rational agent recognizes - if not explicitly in her reasoning - that though the question "Do I believe that $p$ ?" and the question "Is it the case that $p$ ?" have, for her, the same assertibility conditions, they have different truth conditions. (Hence, she recognizes that her capacity correctly to answer a question of the form "Is it the case that $p$ ?" is unreliable in a way that her capacity to answer a question of the form "Do I believe that $p$ ?" is not.) If this is right, then the interpreter's presumption of rationality comprises the presumption that the reasoning agent recognizes the subjective aspect of belief in her deliberations. The interpreter's third-person stance and its success presuppose that the distinction between merely believing that $p$ and its really being the case that $p$ is a distinction made from within the first-person stance of the reasoning agent. Contrary to Brandom, in order to possess the concept of objectivity it is not necessary to engage in the practice of interpersonal reasoning because possession of the concept is independently integral to the practice of intrapersonal reasoning. ${ }^{30}$

\section{Department of Philosophy \\ Loyola University New Orleans}

\section{NOTES}

1 Broadly speaking, the notion of idiolect is that of language as spoken by an individual speaker. As Richard Heck (forthcoming A) writes: "An idiolect ... belongs to a single individual, in the sense that one's idiolect reflects one's own linguistic capabilities and, in this sense, is fully determined by facts about oneself." The notion of sociolect, by contrast, is that of language as historically common to a group of speakers. Examples include English, Russian, and Turkish. In between these two main competing notions of language there is presumably room for a variety of notions of shared language with a lower-profile than that of sociolect, e.g. that of a regional dialect or a lingo used in a corporation or club. Hence, it is possible for one to be committed to the primacy of some notion of shared language whose spatial, temporal, and demographic boundaries are more precisely specifiable than that of sociolect. Thanks to Richard Heck for helpful discussion of this point.

2 This version of the debate, I should note, presumes the existence of both idiolects and sociolects qua objects of philosophical inquiry. For skepticism about the existence of sociolects, see Chomsky, 2000. For views that attribute theoretical primacy to the notion of sociolect, see Dummett, 1978, 1991, 1993, and Wiggins, 1997.

3 Many of Davidson's articles written in defense of this view have been collected in Davidson, 2001a. Page references for the following papers will be to that volume: "Empirical Content" (1982), "A Coherence Theory of Truth and Knowledge" (1983), "Epistemology Externalized" (1990), "Three Varieties of Knowledge" (1991), "The Second Person" (1992), and "The Emergence of Thought" (1997).

4 See "A Nice Derangement of Epitaphs" (1986) and "The Social Aspect of Language" (1994), recently reprinted in Davidson, 2005.

5 For recent defense of the view that the notion of common language does not play a role in explaining communicative success, see Heck forthcoming A. 
6 Indeed, Davidson denies that there are any semantic norms. See Bilgrami, 1992; Davidson, 1993, 1994/2005; and Wikforss, 1999.

7 According to Brandom, Davidson only provides the form of the argument. "Turning it into an actual argument," a central undertaking in Making It Explicit, "requires filling in various notions of content, of objective representational correctness of content, of practical acknowledgement of the significance of the assessments of correctness of content, and so on" (Brandom, 1994, p. 153).

8 It is the idea of using a deontological vocabulary of commitments and entitlements to classify linguistic behavior under what (on pain of explanatory circularity) is supposed to be non-intentional description, in particular, that I think is problematic. The reason is that it is only qua rational agent - a being with beliefs, desires, and other intentional attitudes that a person has commitments and entitlements. Indeed, it is only under intentional description that what a person does can intelligibly be classified either as in keeping with or in violation of a commitment and, so, as correct or incorrect. "[M]aking a mistake," as Davidson writes, "must be doing something with the intention of achieving a result that is not forthcoming" (1980, p. 46, my emphasis). Similarly, Kant's point in identifying the intentional or rational, as opposed to causal, order with "the realm of freedom" is that it is only qua rational agent that a person is intelligibly subject to norms. If this is right, if our capacity for normative understanding gets its grip on linguistic behavior only under intentional description, then there simply is no deontological via media between employment of a purely "physicalistic or other naturalistic vocabulary" and employment of an "intentional vocabulary with semantic locutions" to provide a theoretical characterization of the relation between meaning and use. At any rate, it is hard to see in the first place how 'pragmatic' talk of attributing commitments and entitlements to claims - or of treating or taking a speaker to be committed or entitled to a claim - could conceivably be classified as non-intentional.

9 Jason Bridges (forthcoming) acknowledges the Kantian flavor of Davidson's argument in calling its conclusion 'transcendental externalism.'

${ }^{10}$ Davidson states: "my view differs from what a lot of people say, i.e., it certainly differs from Burge's idea, and it differs from Dummett's. They both think that what a speaker means by his words depends very heavily on how the community uses those words, whether the speaker knows what that is or not. I think it's a lot of foolishness, because it has nothing to do with success in communication. If you don't speak the way the community does and someone figures that out, then you can communicate all day long" (Glüer, 1995, p. 81).

${ }^{11}$ Burge writes: "Language is social in that interaction with other persons is psychologically necessary to learn language. Some philosophers have made the further claim that there is some conceptually necessary relation between learning or having a language and being in a community. I do not accept this view. I assume only that it is a psychologically important fact that we cannot learn language alone" (1989, p. 175).

${ }^{12}$ Also see "Real Patterns" in Dennett, 1998.

${ }^{13}$ I might also add to this list of preliminary remarks that empirical evidence available from developmental psychology, linguistics, cognitive science, and cognitive ethology casts serious doubt on the a priori story Davidson and Brandom tell about the relation between communication, language, and thought. For a review of relevant findings, see Tomasello, 1999; Tomasello, 2003; Tomasello et al., 2005; and Eilan et al., 2005.

${ }^{14}$ Brandom refers to the idea that perceptual judgment must be conceived as rationally constrained by the perceptible facts as the 'rational-constraint constraint' on theories of perception (1996, p. 245). I might note that the requirement, so characterized, seems hardly a constraint. It is not as though responsibility to how things stand in the perceptible environment were a merely optional part of the concept of perception or perceptual belief. A 
theory of perception that somehow managed to contravene the rational-constraint constraint would hardly deserve to be called a theory of perception.

${ }^{15}$ The distinction between what I am calling 'rational responsibility' and 'rational responsiveness' is not explicit in Mind and World, but I think it is in keeping with McDowell's discussions of minimal empiricism there and elsewhere. It also helps to clarify what is at issue between McDowell, Brandom, and Davidson.

${ }^{16}$ It is important to emphasize that McDowell - like Davidson and Brandom - would restrict the realm or 'logical space' of rational responsibility to the realm of conceptual representational contents, and this will be assumed throughout in discussion below. I think that with this (quite strong) restriction in place, minimal empiricism is indeed, as McDowell claims, indisputable. However, I do not see that there is any necessary connection between rational responsibility and rational responsiveness if it is permissible to extend the realm of the former so as also to encompass nonconceptual representational contents. See Peacocke, 1998; Heck, 2000; and Heck, forthcoming B.

${ }^{17}$ For Davidson, as for Quine, observation sentences play a special role in both the philosophy of language and epistemology: they are first in the order of language acquisition - learning the use of the simplest observation sentences is prior to learning the use of all other sentences - and last in the order of justification. As Davidson writes, "there is a perfectly good sense in which certain perceptual sentences are for me epistemically prior: they are an entering wedge into language, and perceptual sentences generally are what connect empirical thought and talk to the world" (Kotatko et al., 2001, p. 291). It is thus fundamental that Davidson be able to show that rejection of the second idea comprised by minimal empiricism does not lead to rejection of or inability to render intelligible the first.

${ }^{18}$ For a similar version of this argument, see Davidson, 1999. One response here is that Davidson curiously ignores Darwin. That is, insofar as the putative challenge of determining the relevant content-determining cause of a creature's reactions is formulated using such biological-functional notions as animal, stimulation, response, sensory surface, etc., there is an answer forthcoming from evolutionary biology (an answer, moreover, that obviates all need to bring in a second creature). Indeed, bio- or teleosemantics is premised on this very idea (Millikan, 1993, 2004). It is also worth noting in this connection that it is an essentially Darwinian solution that Quine ultimately provides to the epistemological problem of how ostensive learning and radical interpretation are possible. The harmony of human intersubjective responses of perceptual similarity, Quine suggests, "is caused by neither interaction nor anatomical homologies. It is preestablished by natural selection, which has favorably slanted the inductive expectations of our forebears down the ages by molding their innate standards of perceptual similarity to mesh with environmental trends. Thus it is that translators and experimenters can blithely ply their distal trades and no questions asked" (Quine, 1999, p. 75, my emphasis). For relevant externalist considerations involving the notion of natural selection, see Burge, 1986.

As Ruth Millikan would likely point out, the real culprit here is Davidson's assumption that, in the epistemically most basic sorts of cases, utterances and beliefs are about what typically causes them. (See Appendix B "What Has Natural Information to Do with Intentional Representation?" in Millikan, 2000.) The problem is that the assumption focuses on the conditions and physical mechanisms of representation production. By contrast, Millikan's teleosemantical approach focuses on the biological mechanisms of representation consumption. In particular, her approach focuses on what correspondences must be assumed to obtain between representational vehicles of a certain type and the environment if consumer systems are to fulfill their proper biological function. What determines the relevant cause of a creature's responses - and, so, its intentional content - cannot 
be settled on the basis of the creature's occurrent properties and dispositions considered quite apart from their phylogenesis, i.e. the evolutionary mechanisms responsible for their present existence. Thus, as Quine suggests in passage quoted above, it is natural selection and not interaction between creatures that solves Davidson's distality problem. In closing this long note, I would also remark that were Davidson actually to formulate the problem in purely physicalistic terms - thereby prescinding from all use of biological-functional notions - it would genuinely have no answer.

${ }^{19}$ See Davidson, 1992/2001a, pp. 111-117 and Davidson, 1991/2001a, p. 209.

${ }^{20}$ Peacocke, 2005, pp. 307-308. What distinguishes full joint attention from mere joint attention is expressed in condition (b). In full joint attention, not only does the state of joint attention have mutual open-ended perceptual availability to $x$ and $y$, but they are also both aware that it does. In paradigmatic cases of successful communication, it seems clear that full joint attention to the meaning of an utterance is involved. So it is full joint attention that Davidson must be claiming is a necessary condition of the existence of language and thought.

${ }^{21}$ Brandom (1995) uses 'belief*' to refer to proto- or quasi-intentional mental states attributable to non-linguistic animals on the basis of their reliable differential responsive dispositions. I am using 'schmelief' here in a similar way.

${ }^{22}$ I should mention that I think Blackburn (1981) is simply wrong on exegetical grounds to attribute such a picture of language to the later Wittgenstein and that what Blackburn refers to as 'publicity,' i.e., communal agreement, plays no such magical role in Wittgenstein's thinking about meaning and understanding. Although the point requires careful elaboration, I would suggest that, for the later Wittgenstein, the concept of intersubjective agreement is no more fundamental than that of judgment itself. See Diamond, 1989 and Minar, 1991.

${ }^{23}$ See, e.g. "The Emergence of Thought" (1997), reprinted in Davidson, 2001a, and "What Thought Requires" (2001), reprinted in Davidson, 2004.

${ }^{24}$ By 'individualism' in this context Brandom intends not semantic internalism, but simply the repudiation of the idea that language and thought are socially constituted in the specific manner suggested by the communication thesis.

${ }^{25}$ One important implication of this is that certain substitutions of singular terms in the claim may be warranted from the perspective of the one attributing the claim, but not from the perspective of the one to whom the claim is attributed.

${ }^{26}$ Objectivity is thus reconstrued, as Brandom says in one of the better-known passages from the book, "as consisting in a kind of perspectival form, rather than in a nonperspectival or cross-perspectival content. What is shared by all discursive perspectives is that there is a difference between what is objectively correct in the way of concept application and what is merely taken to be so, not what it is - the structure, not the content" (1994, p. 600).

${ }^{27}$ David Finkelstein has questioned to what extent Moran's transparency-based model of self-knowledge can plausibly be extended beyond the case of belief. See the postscript "Deliberation and Transparency" to Finkelstein, 2003.

${ }^{28}$ See "Making Sense of Ourselves" and "When Frogs (and Others) Make Mistakes" in Dennett 1987.

${ }^{29}$ The example is from Evans, 1982, p. 225.

${ }^{30}$ For helpful comments on early versions of this paper, I would like to thank Bill Bracken, Justin Bridges, Dan Dahlstrom, Juliet Floyd, Aaron Garrett, Larry Hardesty, Richard Heck, Dasha Polzik, David Wiggins, and an audience at UC Riverside in November 2005. I am also grateful to Aidan Gray and Rachel Goodman for lively discussions of Davidson. 


\section{REFERENCES}

Bilgrami, A. (1992). Belief and Meaning. Oxford: Blackwell.

Blackburn, S. (1981). "Rule-following and Moral Realism," in S. Holtzman and C. Leich (eds.) Wittgenstein: To Follow a Rule. London: Routledge and Kegan Paul.

Brandom, R. (1994). Making It Explicit. Cambridge, MA: Harvard University Press.

Brandom, R. (1995). "Knowledge and the Social Articulation of the Space of Reasons," Philosophy and Phenomenological Research 55, pp. 895-908.

Brandom, R. (1996). "Perception and Rational Constraint: McDowell's Mind and World," in E. Villanueva (ed.) Perception. Atascadero, CA: Ridgeview.

Brandom, R. (1998). "Perception and Rational Constraint," Philosophy and Phenomenological Research 58, pp. 369-374.

Brandom, R. (2002). Tales of the Mighty Dead: Historical Essays in the Metaphysics of Intentionality. Cambridge, MA: Harvard University Press.

Brewer, B. (1999). Perception and Reason. Oxford: Oxford University Press.

Bridges, J. (forthcoming). "Davidson's Transcendental Externalism," Philosophy and Phenomenological Research.

Burge, T. (1986). "Individualism and Psychology," The Philosophical Review 95, pp. 3-45.

Burge, T. (1989). "Wherein is Language Social?," in A. George (ed.) Reflections on Chomsky. Oxford: Blackwell.

Campbell, J. (2002). Reference and Consciousness. Oxford: Oxford University Press.

Child, W. (1994). Causality, Interpretation, and the Mind. Oxford: Oxford University Press.

Chomsky, N. (2000). New Horizons in the Study of Language and Mind. Cambridge: Cambridge University Press.

Davidson, D. (1980). "Agency," in Essays on Actions and Events. Oxford: Oxford University Press.

Davidson, D. (1989). "Conditions of Thought," in J. Brandl and W. Gombocs (eds.) The Mind of Donald Davidson. Amsterdam: Rodopi.

Davidson, D. (1993). "Reply to Akeel Bilgrami," in R. Stoecker (ed.) Reflecting Davidson. Berlin: Walter de Gruyter \& Co.

Davidson, D. (1999). "Interpretation: Hard in Theory, Easy in Practice," in Mario De Caro (ed.) Interpretations and Causes: New Perspectives on Donald Davidson's Philosophy. Netherlands: Kluwer Academic Publishers.

Davidson, D. (1982/2001a). "Empirical Content," in Subjective, Intersubjective, Objective. Oxford: Oxford University Press.

Davidson, D. (1983/2001a). "A Coherence Theory of Truth and Knowledge," in Subjective, Intersubjective, Objective. Oxford: Oxford University Press.

Davidson, D. (1990/2001a). "Epistemology Externalized," in Subjective, Intersubjective, Objective. Oxford: Oxford University Press.

Davidson, D. (1991/2001a). "Three Varieties of Knowledge," in Subjective, Intersubjective, Objective. Oxford: Oxford University Press.

Davidson, D. (1992/2001a). "The Second Person," in Subjective, Intersubjective, Objective. Oxford: Oxford University Press.

Davidson, D. (1997/2001a). "The Emergence of Thought," in Subjective, Intersubjective, Objective. Oxford: Oxford University Press.

Davidson, D. (2001b). "Externalisms," in P. Kotatko, P. Pagin, and G. Segal (eds.) Interpreting Davidson. Stanford: CSLI Publications.

Davidson, D. (2001/2004). "What Thought Requires," in Problems of Rationality. Oxford: Oxford University Press.

Davidson, D. (1986/2005). "A Nice Derangement of Epitaphs," in Truth, Language, and History. Oxford: Oxford University Press. 
Davidson, D. (1994/2005). "The Social Aspect of Language," in Truth, Language, and History. Oxford: Oxford University Press.

Dennett, D. (1987). "Reflections: Real Patterns, Deeper Facts, and Empty Questions," in The Intentional Stance. Cambridge, MA: MIT Press.

Dennett, D. (1998). Brainchildren. Cambridge, MA: MIT Press.

Diamond, C. (1989). "Rules: Looking in the Right Place," in D. Z. Philips and P. Winch (eds.) Wittgenstein: Attention to Particulars. New York: St. Martin's Press.

Dummett, D. (1978). "The Social Character of Meaning," in Truth and Other Enigmas. Cambridge, MA: Harvard University Press.

Dummett, D. (1991). The Logical Basis of Metaphysics. Cambridge, MA: Harvard University Press.

Dummett, D. (1993). "Language and Communication," in The Seas of Language. Oxford: Clarendon Press.

Eilan, N., Hoerl, C., McCormack, T., and Roestler, J. (eds.) (2005). Joint Attention: Communication and Other Minds. Oxford: Oxford University Press.

Evans, G. (1982). The Varieties of Reference. Oxford: Oxford University Press.

Finkelstein, D. (2003). Expression and the Inner. Cambridge, MA: Harvard University Press.

Fodor, J. (1990). A Theory of Content and Other Essays. Cambridge, MA: MIT Press.

Fodor, J. and LePore, E. (1992). Holism: A Shopper's Guide. Cambridge, MA: MIT Press.

Glüer, K. (1995). "Relations and Transitions: An Interview with Donald Davidson," dialectica 49 , pp. $75-86$.

Heck, R. (2000). "Nonconceptual Content and the 'Space of Reasons'," The Philosophical Review 109, pp. 483-523.

Heck, R. (forthcoming A). "Idiolects," to appear in a volume for Robert Stalnaker edited by A. Byrne and J. Thomson.

Heck, R. (forthcoming B). "Are There Different Kinds of Content?"

Jacob, P. (1997). What Minds Can Do. Cambridge: Cambridge University Press.

Kotatko, P., Pagin, P., and Segal, G. (2001). Interpreting Davidson. Stanford: CSLI.

Kripke, S. (1982). Wittgenstein on Rules and Private Language. Cambridge, MA: Harvard University Press.

Malle, B., Moses, L., and Baldwin, D. (2001). Intentions and Intentionality: Foundations of Social Cognition. Cambridge, MA: MIT Press.

McDowell, J. (1994). Mind and World. Cambridge, MA: Harvard University Press.

McDowell, J. (1996). "Précis of Mind and World," in E. Villanueva (ed.) Perception. Atascadero, CA: Ridgeview.

McDowell, J. (2002). "Knowledge and the Internal Revisited," Philosophy and Phenomenological Research 64, pp. 97-105.

Millikan, R. (1993). White Queen Psychology and Other Essays for Alice. Cambridge, MA: MIT Press.

Millikan, R. (2000). On Clear and Confused Ideas. Cambridge: Cambridge University Press.

Millikan, R. (2004). Varieties of Meaning. Cambridge, MA: MIT Press.

Minar, E. (1991). "Wittgenstein and the 'Contingency' of Community," Pacific Philosophical Quarterly 72, pp. 203-234.

Moran, R. (2001). Authority and Estrangement: An Essay on Self-Knowledge. Princeton: Princeton University Press.

Peacocke, C. (1998). "Nonconceptual Content Defended," Philosophy and Phenomenological Research 58, pp. 381-388.

Peacocke, C. (2005). "Joint Attention: Its Nature, Reflexivity, and Relation to Common 
Knowledge," in N. Eilan, C. Hoerl, T. McCormack, and J. Roestler (eds.) Joint Attention: Communication and Other Minds. Oxford: Oxford University Press.

Quine, W. V. (1999). "Where Do We Disagree?," in L. E. Hahn (ed.) The Philosophy of Donald Davidson. Chicago: Open Court.

Ramberg, B. (2001). "What Davidson Said to the Skeptic: Anti-Representationalism, Triangulation, and the Naturalization of the Subjective," in P. Kotatko, P. Pagin, and G. Segal (eds.) Interpreting Davidson. Stanford: CSLI.

Tomasello, M. (1999). The Cultural Origins of Human Cognition. Cambridge, MA: Harvard University Press.

Tomasello, M. (2003). Constructing a Language: A Usage-Based Theory of Language Acquisition. Cambridge, MA: Harvard University Press.

Tomasello, M., Carpenter, M., Call, J., Behne, T. and Moll, H. (2005). "Understanding and Sharing Intentions: The Origins of Cultural Cognition," Behavioral and Brain Sciences 28, pp. 675-735.

Wiggins, D. (1997). "Languages as Social Objects," Philosophy 72, pp. 499-524.

Wikforss, Å. (1999). “Semantic Normativity,” Philosophical Studies 102, pp. 203-226. 